capacity of 5,000 tonnes by 1985 . Now, however, a capacity of only about 2,000 tonnes per year is foreseen for 1984. Although the Brazilian order is only $10 \%$ of the uranium now on order, it will be sold at a profitable price, which is more than can be said of the previous German orders. At the end of March 1978 it became known that Dutch banks were excluded from financing the Brazilian uranium order because only the German and British governments are providing the guarantees.

In the first six months of this year, the matter was discussed extensively four times in the Dutch parliament. In March 30,000 people, some from Germany, demonstrated in Almelo. Two weeks later, 50,000 people from 28 eastern-bloc and western countries took part in a demonstration in Amsterdam against the neutron bomb and nuclear energy. And at the end of June The Hague was the scene of a similar demonstration.

In the meantime it came into the open that the IAEA, at least, had been in favour of a plutonium storage regime. Although such a regime cannot be set up for a few years, an ad hoc regime in Brazil on the basis of an available blue print seemed feasible. What was needed to put the scheme into practice was the political will of the countries concerned, said IAEA deputy secretary general Fischer on Dutch television. A proposal for such a regime would be judged positively by the IAEA board on which 35 countries are represented. However, so far the Urenco partners have not requested an international storage scheme for plutonium.

In an international safeguards system, there would be regional depots for plutonium but probably not in Brazil. In an ad hoc regime with Urenco such a depot could be in Brazil. Brazil will therefore be against a world storage regime.

The whole affair came to an end with the government's decision at the end of June. The motion adopted by the majority of parliamentarians in January required that a storage regime be established before the first delivery of uranium takes place. The final agreement, which states that a storage regime must be available when re- processing starts, is less stringent in its requirements.

Now the only reservation is that there should be sufficient certainty, at the moment of delivery of the first uranium, that before reprocessing starts an agreement would be reached on a storage regime. However, parliament may find difficulty in judging the likelihood of such an agreement being reached, leaving the government fairly free to manoeuvre.

What has happened is what Germany and Britain wanted, say the opponents, who also tried other moves to avoid this agreement. The social democrats presented a bill to regulate the future export of all nuclear material, as in the United States; if accepted the bill would also include the deliveries to Brazil.

The net result of the negotiations is that the opposition feel that the whole affair has been a blow to democracy and to attempts to create a proliferation proof society. "We move from coresponsibility to complicity", the spokesman of the opposition (social democrats) said in parliament

Casper Schuuring

\title{
US plans to ban the use of nitrites in food
}

THE US government is planning to introduce a gradual ban on the use of nitrites in food, following the results of studies carried out at the Massachusetts Institute of Technology indicating a "strong suggestion" that nitrites are carcinogenic.

Steps have already been taken to reduce the use of nitrites as preservatives, particularly in cured meat such as bacon and ham, because of evidence that, when cooked and eaten, they can combine with other chemicals to cause carcinogenic nitrosamines..

The latest study, however, which was conducted by Dr Paul Newberne of MIT, is the first to link nitrites directly with cancer. In the study, $13 \%$ of rats fed sodium nitrites developed tumours of the lymph system, compared to only $8 \%$ of those not fed nitrite.

The US Department of Agriculture and the Food and Drug Administration have called the results "statistically significant", and said in a statement last week that the study "leads us to the concern that nitrites may increase the incidence of human cancer."

Under current legislation, both agencies have a range of powers to take action against any food additive suspected of being carcinogenic. However in this instance the government is refraining from acting precipitously partly because of the embarrassment caused by its attempts to ban the use of saccharin, a move on which Congress has since imposed an 18-month moratorium.

An additional factor is that the use of nitrites considerably cuts down the danger of botulism poisoning from preserved meats, and permits greater freedom in shipping and storage. "We must weigh the risk associated with nitrites added to food against the health risk of not adding it" the two agencies said in their statement.

Because of the public health angle, the federal government is considering ways of introducing a gradual ban on the use of nitrites in circumstances where protection against botulism toxics is important, and where alternative safety techniques need to be developed and implemented. There is likely to be a quicker ban on products

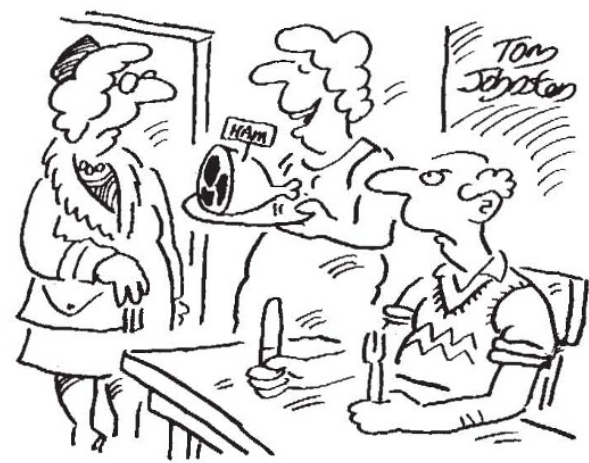

"If I don't get him with cancer, I'll get him with botulism!" that are always cooked thoroughly before they are eaten, since this generally eliminates the chances of botulism poisoning.

In addition to banning nitrites, the government is also proposing to ban the addition of nitrates to processed foods, a move which could, for example, have an impact on the import of cheeses.

The economic impact of a ban on nitrites could be even bigger than that of the proposed ban on saccharin. According to the American Meat Institute, a nitrite ban could "all but destroy the US hog industry, since nearly $70 \%$ of our pork ends up in processed meat products-mostly cured meats." Annual consumption of such products in the US is currently about $\$ 12.5$ billion.

In the light of such a potential impact, measures to forestall a ban on nitrites were introduced into the US Congress last Thursday by Representative James Martin of North Carolina and Representative William Wampler of Virginia.

The two Congressmen are seeking to block any ban until at least three months after the government completes its current investigations into other suspected carcinogens, including saccharin. The issue is not likely to be debated this year, but could become a hot topic when the new Congress meets after the fall elections.

David Dickson 